\title{
Time to celebrate!
}

\author{
Ari A. Mennander, MD, PhD
}

From Tampere University Heart Hospital, Tampere, Finland.

Disclosures: Author has nothing to disclose with regard to commercial support.

Received for publication Nov 4, 2017; accepted for publication Nov 13, 2017; available ahead of print Dec 6, 2017.

Address for reprints: Ari A. Mennander, MD, PhD, Tampere University Heart Hospital, SDSKIR, Tampere PL 2000, Finland (E-mail: ari.mennander@sydansairaala.fi).

J Thorac Cardiovasc Surg 2018;155:1659-60

$0022-5223 / \$ 36.00$

Copyright (C) 2017 by The American Association for Thoracic Surgery

https://doi.org/10.1016/j.jtcvs.2017.11.041

The Finns were caught off guard in November 1939, when the Soviet Red Army attacked Finland without a declaration of war. Despite the outnumbered enemy, the Finns resisted and were able to keep their freedom and homeland. To this day, the Finns refer to the spirit of Winter war; even an overwhelming threat may be repelled by the use of subtle strategy based on teamwork.

The interesting article "Ethyl Pyruvate Is Renoprotective Against Ischemia-Reperfusion Injury Under Hyperglycemia" by Jun and colleagues ${ }^{1}$ in this issue of the Journal describes the overwhelming inflammatory insult caused by renal ischemia-reperfusion injury (IRI) and hyperglycemia, leading to apoptosis and tissue destruction. Sprague-Dawley rats underwent renal IRI by clamping the renal artery for 45 minutes. Some rats were rendered hyperglycemic before IRI, and some received ethyl pyruvate for treatment. It was found that IRI and hyperglycemia up-regulated high-mobility group box 1 protein (HMGB1), which in turn was inhibited by ethyl pyruvate administered either before or after induction of IRI.

Ethyl pyruvate has a role in controlling the detrimental impact of IRI. ${ }^{2,3}$ The molecular pathway associated with HMGB1 includes the regulation of Toll-like receptors and nuclear factor kappa-light-chain enhancer of activated B cells (NF-kB), resulting in the up-regulation of interleukin-1b, tumor necrosis factor- $\alpha$, proapoptotic Bax, and antiapoptotic Bcl-2, all favoring a proinflammatory state caused by IRI. ${ }^{1-3}$ Hyperglycemia adds to the upregulation of this aforementioned molecular pathway. ${ }^{4}$ The well-designed experimental approach facilitated the control of confounding parameters.

The experimental setup may oversimplify the clinical reality. These results may not be extrapolated to describe the significance of cardiopulmonary bypass, concomitant procedures, role of insulin during hyperglycemia, or other medication. The model offers a view to investigate the outcome of renal IRI induced by clamping and releasing the renal arteries. Shorter ischemia time and subsequent

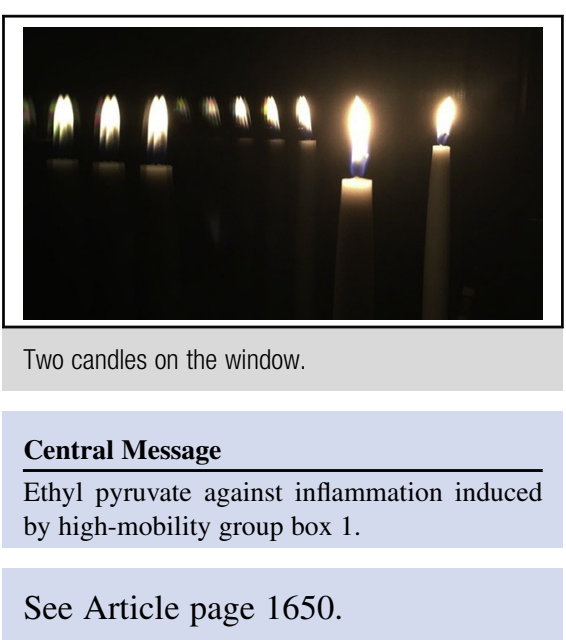

reperfusion interact beneficially against remote myocardial injury, defined as pre- or postconditioning effect. ${ }^{5}$ The results of the study cannot be generalized to doom all ischemic intervention. HMGB1 may also have a biphasic role and induce late protection, at least after brain injury. It remains to be explained why NF-kB was not increased during hyperglycemia as in IRI. In other words, may apoptosis during hyperglycemia occur without impact on NF-kB? It is anticipated that hyperglycemia potentiates inflammation, including every step of the HMGB1 pathway during IRI.

The recent experimental study by Jun and colleagues wakens us to study protection of an adjunct organ such as the kidney during cardiovascular surgery. The kidneys are sensitive to early histologic changes due to IRI, inflammation and subsequent tissue destruction such as apoptosis. In short, the combination of hyperglycemia and IRI may violently and unexpectedly influence patient outcome after cardiovascular surgery. A relatively simple but astute means using ethyl pyruvate may favorably suppress the complex inflammatory cascade during IRI.

A century of Finnish independence is celebrated on December 6, 2017, by lighting 2 candles placed on the windowsill.

\section{References}

1. Jun JH, Song JW, Shin E-J, Kwak Y-L, Choi N, Shim J-K. Ethyl pyruvate is renoprotective against ischemia-reperfusion injury under hyperglycemia. $J$ Thorac Cardiovasc Surg. 2018;155:1659-60.

2. Shen M, Lu J, Dai W, Wang F, Xu L, Chen K, et al. Ethyl pyruvate ameliorates hepatic ischemia-reperfusion injury by inhibiting intrinsic pathway of apoptosis and autophagy. Mediators Inflamm. 2013;2013:461-536. 
3. Hu X, Cui B, Zhou X, Xu C, Lu Z, Jiang H. Ethyl pyruvate reduces myocardial ischemia and reperfusion injury by inhibiting high mobility group box 1 protein in rats. Mol Biol Rep. 2012;39:227-31.

4. Liu L, Jiang Y, Steinle JJ. Inhibition of HMGB1 protects the retina from ischemiareperfusion, as well as reduces insulin resistance proteins. PLoS One. 2017;12:1-10.
5. Hausenloy DJ, Yellon DM. Preconditioning and postconditioning: underlying mechanisms and clinical application. Atherosclerosis. 2009;204:334-41.

6. Tian X, Sun L, Feng D, Sun Q, Dou Y, Liu C, et al. HMGB1 promotes neurovascular remodeling via Rage in the late phase of subarachnoid hemorrhage. Brain Res. 2017;1670:135-45. 